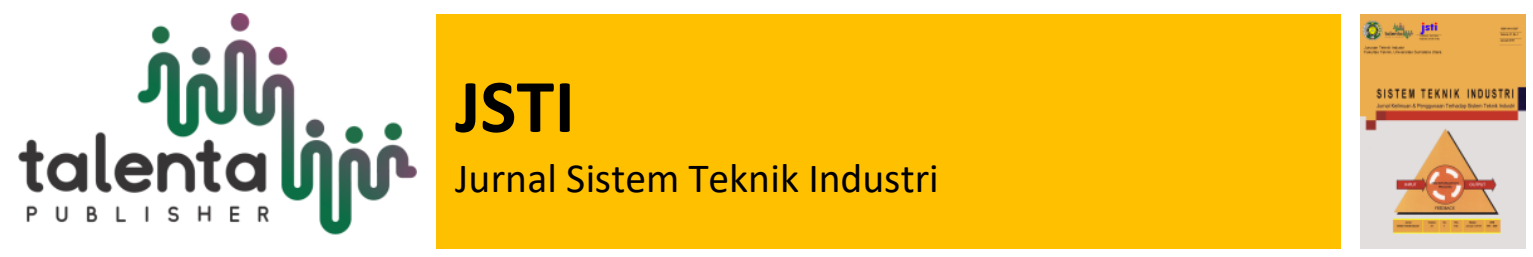

\title{
Pembelian Bahan Baku Optimal Ready Mix Concrete dengan Metode Economic Order Quantity
}

\author{
Andri Nasution, Claudia Indriya Ningrum \\ 1,2, Program Studi Teknik Industri, Fakultas Teknik, Universitas Sumatera Utara,Medan, Indonesia
}

\begin{abstract}
PT. Kreasibeton Nusapersada is a manufacturing plant ready mix concerete and other products such as piles, ryol and udit. This concrete processing requires materials such as a mixture of gravel, cement, sand and addictive substances. The company has a permanent supplier to supply cement, gravel, sand and addictive substances. To find out the optimal amount in purchasing raw materials and the amount of inventory, uses economic order quantity method. Based on the calculation, safety stock for cement is 22.7 tons / day, sand is 16.15 tons / day, stone 2-3 is 13.69 tons / day, stone 1-2 is 18.5 tons / day, guli is 9.27 tons / day at the point where the company had to re-order when cement amounted to 119 tons in silos, sand amounted to 480 tons in stock yards, stones 2-3 amounted to 300 tons in stock yards, stones 1-2 amounted to 259 tons in stock yard and guli amounted to 60 tons in stock yard.
\end{abstract}

Keyword: Ready Mix Concrete, EOQ, Safety Stock, Reorder Point

\begin{abstract}
Abstrak. PT. Kreasibeton Nusapersada merupakan perusahaan pabrik pengolahan ready mix concerete dan produk lainnya seperti tiang pancang, ryol dan udit. Pengolahan beton ini membutuhkan material seperti campuran antara kerikil, semen, pasir dan zat adiktif. Perusahaan memiliki supplier tetap untuk memasok bahan-bahan semen, kerikil, pasir dan zat adiktif. Untuk mengetahui jumlah optimal dalam pembelian bahan baku dan jumlah persediaan.. Berdasrkan perhitungan safety stock untuk semen yaitu 22,7 ton/ hari, pasir 16,15 ton/hari, batu 2-3 yaitu 13,69 ton/hari, batu 1-2 yaitu 18,5 ton/hari, batu guli yaitu 9,27 ton/hari dengan titik dimana perusahaan harus memesan ulang kembali pada saat semen berjumlah 119 ton di silo, pasir berjumlah 480 ton di stock yard,batu 2-3 berjumlah 300 ton di stock yard, batu 1-2 berjumlah 259 ton di stock yard dan batu guli berjumlah 60 ton di stock yard..
\end{abstract}

Kata Kunci: Beton Cair, EOQ, Persediaan Pangan, Titik Balik Pesan

Received 13 May 2020 | Revised 12 March 2019| Accepted 13 May 2020

\section{Introduction}

PT. XYZ adalah perusahaan manufaktur yang memproduksi Ready Mix Concrete. Adapun dalam.proses produksinya perusahaan tidak memiliki kebijakan dalam pembelian bahan baku sehingga akan mempengaruhi total biaya produksi, sehingga dengan adanya metode Economic Order Quantity dapat diketahui jumlah pembelian bahan baku yang optimal.

*Corresponding author at: Medan, Indonesia

E-mail address: ihun_mama@yahoo.co.id

Copyright (C) 2020 Published by Talenta Publisher, ISSN: 1411-5247 e-ISSN: 2527-9408

Journal Homepage: http://talenta.usu.ac.id/jsti 
Supply chain merupakan jaringan perusahaan-perusahaan bekerja secara ibersama-sama untuk menciptakan dan menghantarkan suatu produk ke tangan pemakai akhir. Perusahaan-perusahaan tersebut biasanya termasuk supplier, pabrik, distributor, ritel, serta perusahaan-perusahaan pendukung seperti perusahaan jasa logistik.

Penggunaan metode Supply Chain Management dalam bentuk pengendalian persediaan, perusahaan akan mengalami masalah jika tidak terdapat pengendalian persediaan yang tidak tepat, didalam memenuhi kebutuhan konsumen baik dalam bentuk barang maupun jasa yang dihasilkan oleh perusahaan tersebut. Perusahaan harus memiliki kebijakan dalam menentukan jumlah persediaan barang yang akan di pakai dalam proses produksi, perusahaan akan mengalami kerugian akibat biaya yang tidak semestinya dikeluarkan oleh karena tanpa adanya manajemen yang tepat.Studi Literatur

\section{Tinjauan Pustaka}

Persediaan merupakan salah satu aset yang dimiliki perusahaan yang harus dikelola dengan baik. Bagian utama daran neraca dab sering kali merupakan perkiraan yang nilainya cukup besar yang melibatkan modal kerja yang besar tanpa adanya persediaan barangan dagangan,.

\subsection{Pengertian Pengendalian Persediaan}

Pengendalian persediaan merupakan kegiatan untuk mengontrol jumlah persediaan bahan dan persediaan barang jadi, perusahaan dapat menghindari tergangunya proses produksi dan menentukan peenjualan optimal dan pembeliannya

Persediaan yang optimal akan dapat dicapai apabila mampu menyeimbangkan beberapa faktor mengenai kuantitas produk, daya tahan produk, panjangnya periode produksi, fasilitas penyimpanan dan biaya penyimpanan persedian, kecukupan modal, kebutuhan waktu distribusi, perlindungan mengenai kekurangan tenaga kerja, perlindungan mengenai kekurangan harga bahan dan perlengkapan serta resiko yang ada dalam persediaan.

Bentuk utama dari persediaan perusahaan yaitu persediaan bahan mentah, persediaan barang dalam proses dan persediaan barang jadi. Dibutuhkan suatu pengendalian persediaan yang efisien untuk dapat menjamin tersedianya setiap persediaan tersebut. Penghematan biaya produksi ini akan berdampak pada harga jual barang atau jasa dan laba perusahaan, Perusahaan harus mencari strategi yang tepat agar biaya produksi dapat optimal.

Pengendalian terhadap persediaan bahan baku yang dilakukan secara tepat oleh perusahaan agar perusahaan dapat mempertahankan posisinya atau bahkan manaikkan posisinya dalam persaingan bisnis. Adanya pengendalian persediaan bahan baku dapat membantu perusahaan agar perusahaan memiliki tingkat keefisienan yang tinggi dalam penggunaan bahan baku.

Dalam pengendalian persediaan baik bahan baku maupun produk jadi dapat dilakukan dengan menggunakan metode EOQ. Perhitungan menggunakan metode EOQ terdiri dari biaya 
pemesanan, biaya penyimpanan dan biaya pembelian. Biaya pemesanan diperoleh langsung dari perusahaan dengan total selama setahun. Biaya penyimpanan diestimasi berdasarkan ratarata penyimpanan barang selama satu tahun

Tujuan pengendalian persediaan bahan baku adalah untuk menekan biaya-biaya operasional seminimal mungkin sehingga kinerja dan keuntungan perusahaan lebih optimal. Biaya operasional ini adalah biaya persediaan yang terdiri dari biaya pemesanan dan biaya penyimpanan. Untuk melaksanakan pengendalian persediaan yang dapat diandalkan dan dipercaya tersebut maka harus diperhatikan berbagai faktor yang terkait dengan persediaan. Penentuan dan pengelompokan biaya-biaya yang terkait dengan persediaan perlu mendapatkan perhatian yang khusus dalam mengambil keputusan yang tepatModel persediaan yang paling banyak digunakan salah satunya adalah model kuantitas pesanan ekonomis (Economic Order Quantity). Metode EOQ berusaha mencapai tingkat persediaan seminimum mungkin, biaya rendah dan mutu yang lebih baik. Perencanaan persediaan yang menggunakan metode EOQ mampu meminimalisasi terjadinya out of stock sehingga tidak mengganggu proses produksi dalam perusahaan dan mampu menghemat biaya persediaan bahan baku dalam perusahaan. Penerapan metode EOQ pada perusahaan diharapkan akan mengurangi resiko yang dapat ditimbulkan karena persediaan yang berlebihan didalam ruang penyimpanan atau gudang.

EOQ adalah jumlah dimana setiap kali pembelian akan memperoleh total biaya persediaan yanpaling murah. Selain mententukan EOQ perusahaan juga perlu menentukan waktu pemesanan kembali bahan baku yang akan digunakan atau Reorder Point (ROP) agar pembelian bahan yang sudah ditetapkan dalam EOQ tidak mengganggu kelancaran kegiatan produksi. Yang dimaksud dengan ROP adalah titik dimana jumlah persediaan menunjukkan waktunya untuk mengadakan pesanan kembali. EOQ digunakan sebagai bagian dari sistem inventaris peninjauan berkelanjutan. Sistem EOQ menyediakan suatu aturan yang tidak hanya mencakup menghitung peluang pemesanan ulang, namun jumlah pemesanan ulang yang dilakukan juga. Biasanya, seseorang yang bertanggung jawab dalam urusan inventaris di sebuah perusahaan akan memantau tingkat persediaan yang dimiliki perusahaan. Jumlah persediaan dipantau setiap saat karena ada peluang pembeli melakukan pemesanan ulang. Pada sistem tersebut dibutuhkan penghitungan EOQ yang jeli dan teliti. Penghitungannya tidak boleh kurang dan harus sesuai dengan kondisi yang ada. Penerapan sistem EOQ dibutuhkan sebuah perusahaan karena manfaatnya terbilang baik dalam menunjang keberlanjutan sebuah usaha. Berikut rincian manfaat penghitungan dengan model EOQ:

1) Membantu pemilik usaha kecil membuat keputusan tentang berapa banyak persediaan yangharus disimpan.

2) Membantu pemilik usaha memutuskan berapa banyak barang yang dipesan. 
3) Membantu pemilik usaha mengetahui seberapa sering harus dilakukan pemesanan ulang.

4) Mendapatkan peluang untuk mengeluarkan biaya serendah mungkin.

Melalui EQO atau Economy Order Quantity menjadikan kita bisa mengetahui berapa banyak jumlah yang harus dipesan agar biaya total, dalam hal ini penjumlahan antara biaya pemesanan dan biaya penyimpanan, menjadi seminimum mungkin. Dengan demikian untuk menghitung jumlah pesanan yang ekonomis perlu dilihat pertambahan biaya pemesanan dan biaya penyimpanan serta besarnya persediaan rata-rata. Penghitungan EOQ umumnya didasarkan kepada sejumlah asumsi berikut.

1) Jumlah total unit yang akan dikonsumsi selama periode tersebut diketahui dengan pasti.

2) Total biaya pemesanan tetap konstan selama periode tersebut.

3) Biaya persediaan tetap konstan sepanjang periode.

4) Tidak ada diskon tunai atau jumlah yang tersedia.

5) Seluruh jumlah persediaan yang dipesan dikirim dalam satu batch.

6) Kuantitas optimal untuk setiap item saham atau invariabel dihitung secara terpisah.

7) Waktu tunggu tidak berfluktuasi dan pesanan diterima tepat waktu dengan jumlah pesanan total.

8) Asumsi yang dijelaskan di atas juga dikenal sebagai batasan EOQ.

Penerapan sistem EOQ dibutuhkan sebuah perusahaan karena manfaatnya terbilang baik dalam menunjang keberlanjutan sebuah usaha. Berikut rincian manfaat penghitungan dengan model EOQ:

Tujuan pengendalian bahan baku adalah untuk mengetahui (1) kuantitas optimal dalam setiap kali pembelian bahan baku (EOQ), (2) titik yang menunjukan waktunya untuk mengadakan pemesanan kembali (ROP), (3) persediaan maksimum (Maximum Inventory), dan (4) total biaya persediaan bahan baku (Total Inventory Cost).

Reorder Point ialah saat atau titik dimana harus diadakan pesanan lagi sedemikian rupa sehingga kedatangan atau penerimaan barang yang dipesan itu tepat pada waktu dimana persediaan diatas safety stock sama dengan nol [6] ,

\section{Metodologi Penelitian}

Metode penelitian yang digunakan dalam penentuan persediaan ini adalah metode Economic Order Quantity. Metode Economic Order Quantity dapat menentukan titik pemesanan kembali bahan baku [7] sehingga perusahaan tidak memiliki persediaan yang berlebihan di gudang dan dengan adanya metode ini dapat menentukan stok pengaman sehingga jika pada saat pemesanan bahan baku mengalami kendala maka perusahaan menggunakan stok tersebut sehingga proses produksi berjalan lancer [8]. Berikut merupakan blok diagram dalam penyelesaian masalah seperti pada gambar dibawah ini 


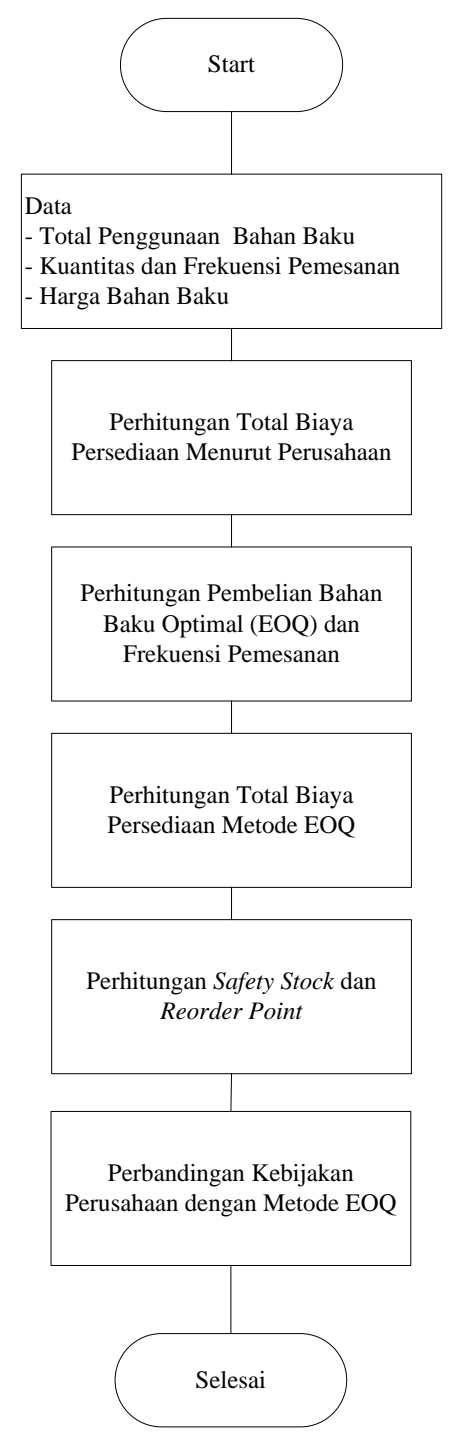

Gambar 1. Blok Diagram Pengolahan

\section{Hasil dan Pembahasan}

\subsubsection{Perhitungan Biaya Persediaan Bahan Baku Menurut Perusahaan}

Berikut ini merupakan tabel total biaya persediaan menurut perusahaan pada periode januari 2020:

Tabel 1. Total Biaya Persediaan Menurut Perusahaan Januari 2020

\begin{tabular}{cccccc}
\hline Keterangan & Semen $(\mathrm{Rp})$ & Pasir $(\mathrm{Rp})$ & $\begin{array}{c}\text { Batu 2-3 } \\
(\mathrm{Rp})\end{array}$ & $\begin{array}{c}\text { Batu 1-2 } \\
(\mathrm{Rp})\end{array}$ & $\begin{array}{c}\text { Batu K. guli } \\
(\mathrm{Rp})\end{array}$ \\
\hline $\begin{array}{l}\text { Total Biaya } \\
\text { Persediaan }\end{array}$ & 69.392 .060 & 70.521 .950 & 50.927 .502 & 56.585 .100 & 52.863 .066 \\
\hline
\end{tabular}

Sumber : Pengolahan Data 


\subsubsection{Perhitungan Biaya Persediaan Metode Economic Order Quantity}

Berikut merupakan tabel total biaya persediaan bahan baku pembuatan Ready Mix Concrete. Tabel dibawah ini merupakan perbandingan antara kebijakan perusahaan dengan metode EOQ:

Tabel 2. Perbandingan Biaya Persediaan Perusahaan dengan Metode EOQ

\begin{tabular}{cccc}
\hline Bahan Baku & Kebijakan Perusahaan $(\mathrm{Rp})$ & Metode EOQ $(\mathrm{Rp})$ & Selisih $(\mathrm{Rp})$ \\
\hline Semen & 69.392 .060 & 16.877 .580 & 52.514 .480 \\
Pasir & 70.521 .950 & 20.901 .519 & 49.620 .431 \\
Batu 2-3 & 50.927 .502 & 10.935 .624 & 39.991 .878 \\
Batu 1-2 & 56.585 .100 & 14.848 .385 & 41.736 .715 \\
Batu Guli & 52.863 .066 & 4.736 .686 & 48.126 .380 \\
\hline
\end{tabular}

Sumber : Pengolahan Data

\subsubsection{Penentuan Persediaan Pengaman (Safety Stock)}

Safety Stock digunakan untuk mengetahui berapa besar perusahaan harus memiliki cadangan bahan baku agar terhindar dari resiko kehabisan persediaan bahan baku yang akan mempengaruhi kelancaran proses produksi Besarnya persediaan pengaman diperlukan data mengenai pemakaian maksimum [9], pemakaian rata-rata dan lead time. Waktu tunggu dalan melakukan pemesanan bahan baku rata-rata selama 1 hari. Berdasarkan dat tersebut dapat dihitung besarnya persediaan pengaman sebagai berikut:

$$
\begin{aligned}
\text { SS Semen } & =(\text { Pemakaian maksimum }- \text { rata-rata }) \times \text { lead time } \\
& =(119-96,23) \times 1 \\
& =22,77 \text { ton/hari } \\
\text { SS Pasir } & =(\text { Pemakaian maksimum }- \text { rata-rata }) \times \text { lead time } \\
& =(480-463,85) \times 1 \\
& =16,15 \text { ton/hari } \\
\text { SS Batu 2-3 } & =(\text { Pemakaian maksimum }- \text { rata-rata }) \times \text { lead time } \\
& =(300-286,31) \times 1 \\
& =13,69 \text { ton/hari } \\
\text { SS Batu 1-2 } & =(\text { Pemakaian maksimum }- \text { rata-rata }) \times \text { lead time } \\
& =(259-240,5) \times 1 \\
& =18,5 \text { ton/hari } \\
\text { SS Batu Guli } & =(\text { Pemakaian maksimum }- \text { rata-rata }) \times \text { lead time } \\
& =(60-50,73) \times 1 \\
& =9,27 \text { ton/hari }
\end{aligned}
$$




\subsubsection{Perhitungan Titik Pemesanan Ulang (Reorder Point)}

Tujuannya agar memberi batasan bagi perusahaan agar memesan kembali bahan baku jika sudah mendekati jumlah yang telah ditetapkan. Besarnya ROP adalah jumlah penggunaan bahan baku dikalikan lead time dan ditambahkan dengan safety stock [10].

$$
\begin{array}{ll}
\text { ROP Semen } & =d \times \mathrm{L}+s s \\
& =96,23 \times 1+22,77 \\
& =119 \text { ton } \\
\text { ROP Pasir } & =d \times \mathrm{L}+s s \\
& =463,85 \times 1+16,15 \\
& =480 \text { ton }
\end{array}
$$

ROP Batu 2-3 $=d \times \mathrm{L}+s s$

$$
\begin{aligned}
& =286,31 \times 1+13,69 \\
& =300 \mathrm{ton}
\end{aligned}
$$

ROP Batu 1-2 $=d \times \mathrm{L}+s s$

$$
\begin{aligned}
& =240,5 \times 1+18,5 \\
& =259 \text { ton } \\
\text { ROP Guli } \quad & d \times \mathrm{L}+s s \\
& =50,73 \times 1+9,27 \\
& =60 \text { ton }
\end{aligned}
$$

Berikut ini merupakan tabel perbandingan ROP yang diterapkan perusahaan dengan metode EOQ sebagai berikut:

Tabel 3. Perbandingan ROP Perusahaan dengan Metode EOQ

\begin{tabular}{cccc}
\hline Bahan Baku & $\begin{array}{c}\text { Kebijakan } \\
\text { Perusahaan (ton) }\end{array}$ & Metode EOQ (ton) & Selisih (ton) \\
\hline Semen & - & 119 & 119 \\
Pasir & - & 480 & 480 \\
Batu 2-3 & - & 300 & 300 \\
Batu 1-2 & - & 259 & 259 \\
Batu Guli & - & 60 & 60 \\
\hline
\end{tabular}

Sumber : Pengolahan Data

\section{Kesimpulan}

Setelah dilakukannya perhitungan dengan metode Economic Order Quantity didapatkan total biaya produksi yang lebih rendah dibandingkan dengan total biaya produksi yang selama ini diterapkan oleh perusahaan. Hal ini dapat menjadi pertimbangan bagi perusahaan agar menggunakan metode Economic Order Quantity untuk menentukan pembelian bahan baku yang optimal untuk proses produksi Ready Mix Concrete. 


\section{REFERENCES}

[1] Enggar. 2017. Analisis Pengendalian Persediaan Bahan Baku Guna Meminimalkan Biaya Persediaan Pada Dunkin Donuts Manado. Universitas Sam Ratulangi Manado

[2] Elsa Olivia. 2016. Analisis Persediaan Bahan Baku Tepung Terigu Menggunakan Metode Eoq(Economic Order Quantity) Pada Roti Puncak Makassar. Universitas Gunadarma

[3] Fajrin, Arizka. 2016. Analisis Pengendalian Persediaan Bahan Baku Dengan Menggunakan Metode Economic Order Quantiti (Eoq) Pada Perusahaan Roti Bonansa. Universitas Negeri Semarang

[4] Ikhwanina. 2017. Analisis Penentu Re-Order Point (Rop) Kedelai Untuk Kelancaran Proses Produksi Tempe Pada Raja Tempe Di Nganjuk Tahun 2015 Universitas Nusantara Pgri Kediri

[5] Juventia, Jesica. 2016. Analisis Persediaan Bahan Baku PT. BS dengan Metode Economic Order Quantity (EOQ). Universitas Pelita Harapan

[6] Misbachul, Dea. 2018. Analisis Efisiensi Biaya Persediaan Menggunakan Metode Eoq (Economic Order Quantity) Pada Pt. Xyz. Universitas Trunojoyo Madura

[7] Nuriszal, Firman. 2019. Perencanaan Persediaan Bahan Baku Untuk Produk Semen Instan Di Pt. Vwx. Sidoarjo

[8] Oki, I Wayan. 2015. Analisis Persediaan Bahan Baku Kacang Koro Pedang (Canavalia Ensiformis)Pada UD Arjuna Bali, Desa Nyanglan, Kecamatan Banjarangkan, Kabupaten Klungkung. Universitas Udayana

[9] Reny, Warisman. Penggunaan Teknik Eoq (Economic Order Quantity)\&Rop (Repeat Order Dalam Upaya Pengendalian Efisiensi Persediaan. Universitas Brawijaya, Malang

[10] Wahyu, Agung. 2016. Penggunaan Metode Economic Order Quantity (Eoq) Dalam Upaya Pengendalian Persediaan Bahan Pembantu. Universitas Brawijaya 